\title{
INSIGHTS: \\ GOVERNANCE, INTEGRITY AND CORRUPTION: A COMMENTARY FROM THE PERSPECTIVE OF HUMAN GOVERNANCE
}

\author{
Arfah Salleh ${ }^{1}$, Anis Matsham Heidecke ${ }^{1}$ \\ ${ }^{1}$ Human Governance Institute Inc., Malaysia
}

ABSTRACT - The National Anti-Corruption Plan (NACP) launched in January 2019 provides a narrative on the imperatives to fight corruption (fasad). Integrity and governance have been identified as the twin solutions to corruption. Based on this foundational premise, various initiatives from six key strategies relating to integrity, transparency and accountability of actors in politics, public administration, law enforcement, legal and judicial domain, corporate sphere and other relevant parties within the Malaysian society have been outlined in the journey towards a corrupt free nation. In comparison with the National Integrity Plan (2004) and the Government Transformation Plan (2010), its two predecessor national frameworks, the NACP, explicitly recognises that integrity is a human issue. As a consequence, it highlights the human dimension that will also be its focus area, thus creating in our view, its differentiating factor. This commentary offers the pathway in addressing the human dimension on integrity and corruption through human governance.

ARTICLE HISTORY

Received: 22-05-2019

Accepted: 10-07-2019

\section{KEYWORDS}

Anti-corruption, governance, integrity plan, human governance

\section{INTRODUCTION}

In view that corruption is frequently analogised as cancer, the manner corruption is treated can also be approached from a similar standpoint. Once diagnosed with this health state, the treatment options available are dependent upon the type and stage of the cancer but these treatments, such as chemotherapy, radiotherapy or others, are different postdiagnosis therapeutic forms and do not act as means for prevention. Preventive measures would be about taking a more holistic effort comprising lifestyle, diet ethics and other relevant steps to well-being. In regard to corruption, it is vital to distinguish society into the incorruptible, corrupt and corruptible. While the corrupt much like cancer cells will need to be weeded out through diagnostic measures and treated with appropriate penalties, the focus on the corruptible can never be over-emphasised. These are our everyday persons: the student, the teacher, the bank officer, the MRT worker, the law enforcer, the policy maker and every other person that may encounter, or have already encountered, situations that may waver our individual integrity. The incorruptible, on the other hand, is a category that can look after themselves for regardless of situation, they will not embark in corruption.

How then do we tackle the corruptible so that they can, when faced with the opportunity to commit corruption, avoid so? The journey starts with being aware and conscious at all times of the thought that influences one's action akin to cancer screening mechanism. But to be able to do that one needs to recognise that it is possible to partake in that process and in the first place, that process is available if one decides to embark on it. Nonetheless, in our current mainstream system which is founded upon Descartes' ideological separation between spirit and body, one's actions tend to be seen as unrelated to the internal thought. The Cartesian model of separation between the res extensa and res cogitans nature of human was later further embodied into human as material physical only in the Darwinian Theory. Rules and regulations and external systems structure are deemed sufficient to "control" the physical body's actions. But is this truly reflective of the nature of human? Do we have to remain in a Cartesian and Darwinian frame of reference or do we have a choice of a different model of reality regarding the nature of human for us to take a different route from that which we have been adopting for umpteen years in the fight against corruption?

This commentary offers some of the choices to help us view corruption through the lens of being human. We wish to highlight that this is not a philosophical paper but one which is practical and founded upon the philosophy of being human modelled contrary to the Cartesian mainstream worldview. Human governance is essentially about being human with governance being a consequence. Hence, key to the whole journey is the knowing and understanding of several aspects of being human: the what, the who and the why. Putting in simple terms, the "what" is concerned with the nature of human - whether physical and/or metaphysical, the "who", about how the role of human is perceived - for instance as steward/trustee or resources for economic activity or as one who exploits others for one's gains and the "why" is about one's purpose in life - such as to solely amass wealth, material acquisitions or for other higher agenda. 
While all three questions are interrelated, for the purpose of institutionalising the human dimension in rolling out the NACP, we focus here on the "what" question given the other two being more individual-centred. On this matter, it is useful to appreciate that there are several models of nature of human that can be made reference to. For instance, Ioi and Uchida in their study of business mergers and acquisitions, made reference to the Japanese four-layered "Ningen" (human) model to understand how human behaviour is influenced. Its outermost layer refers to the external and visible; behaviours and conducts that are observable. This layer is a function of the other three internal layers: the internal and invisible layers of logic and explicit thought as well as layers relating to emotion and tacit thought while the most instrumental layer is the deep psychological layer based on one's view of nature of human being. In the context of identifying success factors between mergers and acquisitions of Western and Japanese organisations, Ioi and Uchida found that in the final analysis, it is about influencing the inner core of the human that can bring change to the culture of practice. Organisations that ignore this fundamental human aspect tend to have problems of cultural assimilation.

Another model offered from the discipline of philosophy by Huston Smith is also four-layered. The four levels on nature of human or selfhood basically comprise the body at the outermost layer, followed by mind, soul and spirit as the innermost layer. William Tiller, himself a material scientist had also put forth a model of nature of human from the perspective of post-modern science. He captures the nature in three layers where the outermost is the personality self; the middle, the soul self; and at its core, the God self. The examples above offer only three alternative models to the hegemonic view on the nature of material only human based on the mainstream Cartesian / Darwinian perspective. What is interesting to note is that these three models of human being despite not founded upon any preferred religious affiliation, show the acceptance of the non-material aspect of human.

In respect to addressing corruption, a useful narrative common among the models is the acceptance that it is the inner dimension of human which is that which influences the outer behaviour. Hence, for any behavioural change, unless the inner dimension is addressed, the behaviour which is the shadow of the inner source will not be changed or if seen to change, is not sustainable. Moving on in the quest to address corruption, we are now opened to several decision choices. But from the previous discussions, we now know that we can and should address the "corruptible" group apart from continuing with the treatment of the "corrupt". Towards this end, we are aware that there has been progress in the human development sphere that questions the very core of the model of nature of human whether from the perspective of business development, philosophy or even science itself. The fact that the metaphysical aspect of human is recognised as connected with the physical material form by authorities from other disciplines not just religion should provide a new window of insight in approaching corruption as a human issue rather than previously tend to be seen as totally a technical one.

As to the NACP, it has identified several specific initiatives (Initiative 2.4, NACP 2019) regarding the need to embed the human dimension. Specifically, the NACP recognises this necessity in the execution of all levels of education and training including teachers' education and continuous professional development programs of corporate and public sector institutions, among others. With this being part of the rollout actions, the hope is that future generations will be able to appreciate the meaning of integrity and consequently live correctly rather than corruptly. So how does human governance appear in this equation? Summing up, in the pursuit to address corruption, human governance serves as a pathway to enhance integrity. And to start the "process", we cannot but return to the foundational meaning of being human, beginning with establishing an awareness of the various models of nature of human which we need to choose. The journey to understanding and actualising human governance is about building one's ability and capacity to connect one's inner self with one's outer dimension. And based on our experience, it is not impossible and neither it is an airy-fairy mumbo jumbo exercise but one underscored by scientific underpinning and evidence. 